\title{
A CIÊNCIA E O NOVO ESTADO DO CONHECIMENTO: a contribuição da Ciência da Informação
}

\author{
THE SCIENCE AND THE NEW CONDITION OF THE KNOWLEDGE: the \\ contribution of the Information Science
}

Raimundo Nonato Macedo dos Santos - rnsantos@puc-campinas.edu.br

Professor do Programa de Pós-Graduação em Ciência da Informação da PUCCAMP

Regiane Alcântara-Eliel - regiane@unicamp.br

Oscar Eliel - oscariol@iel.unicamp.com.br

Mestrandos do Programa de Pós-Graduação em Ciência da Informação da PUCCAMP

\section{Resumo}

Comente este artigo no blog Ebibli = http://encontros-bibli-blog.blogspot.com/

Em face do novo estado do conhecimento, marcado basicamente pela sua despersonalização, credibilidade e fragmentação - decorrência do aumento vertiginoso do volume de informação e do conhecimento existente -, a Ciência da Informação, cujo objeto de estudo é a informação, contribui para a produção do conhecimento científico. Seu objetivo é pesquisar e desenvolver processos e técnicas, apropriando-se de tecnologias de informação, das teorias da cognição e do conhecimento para que a informação produza os efeitos desejados: buscar garantir a apreensão de sentido ou de mudança de estado de consciência em seu significado, ou seja, o conhecimento. Concretiza-se, assim, o caráter social da ciência. Refletindo sobre os fundamentos da Ciência da Informação, pretende-se demonstrar que as operações de construção, comunicação e uso que se processam sobre o seu objeto de estudo materializamse em sistemas de recuperação de informação. Na prática, tais sistemas consistem em colocar em correspondência uma representação de necessidade de um pesquisador, de uma comunidade científica, com uma representação do conteúdo dos documentos, por meio de uma função de comparação que avalia a pertinência e a relevância dos documentos, de forma que as informações recuperadas representem o estado da arte do conhecimento científico em determinado campo do conhecimento.

Palavras-chave: Ciência da Informação; Produção do Conhecimento; Sistemas de Recuperação da Informação.

\section{INTRODUÇÃO}

O presente artigo propõe-se a refletir sobre a contribuição da Ciência da Informação para o desenvolvimento conceitual e metodológico de sistemas de recuperação de informação. Considera que, por meio de processos e técnicas de estruturação, sistematização e representação do conhecimento científico gerado, a Ciência da Informação reflete sobre recursos e dispositivos propulsores de fluxos informacionais para geração de novos conhecimentos e que a essência da ciência é a própria informação. 
Nesse sentido, Le Coadic (2004, p.207), referenciando-se a Descartes, diz que a busca pelo conhecimento deve começar pela busca dos conhecimentos primeiros. Em outras palavras, a busca pelo conhecimento deve começar pelo acesso ao conhecimento já existente, aos princípios que já estão estabelecidos e fundamentados, ou seja, a produção de conhecimento tem início com a busca de informações sobre aquilo que já foi produzido anteriormente. Concordamos com Le Coadic (1996, p. 27) quando afirma que: “[...] a informação é o sangue da ciência. Sem informação, a ciência não pode se desenvolver e viver. Sem informação a pesquisa seria inútil e o conhecimento não existiria.”

A informação, no âmbito da Ciência da Informação, pode ser considerada como estrutura significante que pode promover a geração de novos conhecimentos (Barreto, 1994). Quando assimilada, a informação altera o estado de consciência do indivíduo. Podemos assim dizer que a assimilação da informação - seja ela escrita, oral, audiovisual ou digital - é condição (matéria-prima) para geração de novos conhecimentos.

Brookes representou o papel da informação no processo de produção de novos conhecimentos por meio da "Equação Fundamental da Ciência da Informação", na qual é considerada incremento essencial no processo de construção de conhecimento.

$\mathrm{K}(\mathrm{S})+\delta \mathrm{K}=\mathrm{K}(\mathrm{S}+\delta \mathrm{S})$

$$
\left.\right|_{\delta I}
$$

Silva (2003, p. 24) esclarece que a Equação de Brookes “[...] exprime a passagem de um estado do conhecimento $\mathrm{K}(\mathrm{S})$ para um novo estado de conhecimento $\mathrm{K}(\mathrm{S}+\delta \mathrm{S})$ por meio de um acréscimo de conhecimento $\delta \mathrm{K}$, extraído de um incremento de informação $\delta \mathrm{I}$, indicando $\delta \mathrm{S}$ o efeito dessa modificação no estado inicial de conhecimento.”

Le Coadic (1996) também analisa o processo de construção de conhecimento como um fenômeno intrínseco ao indivíduo, que é gerado a partir da identificação de uma lacuna em nosso estado de consciência. Nesse sentido, o autor considera a informação como propulsora de novos conhecimentos: 
Nosso estado (ou nossos estados) de conhecimento sobre determinado assunto, em determinado momento, é representado por uma estrutura de conceitos ligados por suas relações: nossa 'imagem' de mundo. Quando constatamos uma deficiência ou uma anomalia desse(s) estado(s) de conhecimento, encontramo-nos em um estado anômalo do conhecimento. Tentamos obter uma informação ou informações que corrigirão essa anomalia. Disso resultará um novo estado de conhecimento (LE COADIC, 1996, p. 9-10).

Sendo a informação incremento essencial para construção de novos conhecimentos, e para o desenvolvimento da ciência, assumimos que é indispensável, portanto, garantir o acesso a ela por meio de um sistema de recuperação de informações, que se desenvolve no seio de um vasto domínio de pesquisa envolvendo as Ciências da Informação, Computação, Lingüística, Matemática e das Ciências do Homem e da Sociedade.

\section{A CIÊNCIA COMO SISTEMA SOCIAL}

Sayão (1996) considera que a ciência, como um processo que se apropria de maneira seletiva das contribuições de seus pesquisadores, tem um caráter cumulativo resultante de um corpo de conhecimento baseado em consenso. Pode-se considerar a ciência como um amplo sistema social, no qual, a partir dos conhecimentos consensuais fundamentados e materializados por meio da literatura técnico-científica, cumpre-se a função de disseminação do conhecimento. Tal função possibilita aos pesquisadores fundamentar e refutar questões, estabelecer argumentos, definir pesquisas prioritárias etc, em síntese: promover e gerar novos conhecimentos, resultando, assim, o caráter cumulativo e social da ciência.

Sayão $(1996$, p. 1) considera que para o pesquisador “[...] fundamentar sua questão sobre o que já foi estabelecido é uma imposição do método científico, da natureza tribal e cumulativa da ciência, sem o que o pesquisador está condenado ao limbo da rejeição e do esquecimento e o seu saber ao descrédito."

A fundamentação de um trabalho científico acontece a partir das revisões bibliográficas, sendo este um mecanismo que permite ao pesquisador analisar o estado atual estado da arte - do conhecimento em sua área de atuação. 
Na visão de Alves (1992), a revisão bibliográfica é um instrumento de indiscutível importância para o encaminhamento de uma pesquisa e para a produção de novos conhecimentos. Alves (1992, p. 54) expõe que: “[...] a má qualidade da revisão de literatura compromete todo o estudo, uma vez que não se constitui uma seção isolada, mas, ao contrário, tem por objetivo iluminar o caminho a ser trilhado pelo pesquisador, desde a definição do problema até a interpretação dos resultados."

Parafraseando Le Coadic (2004), verificamos que o pensamento científico necessita, nos diferentes domínios em que é exercido, de princípios diretores que orientem as pesquisas e unifiquem as teorias para pior ou para melhor. Esses marcos da lógica científica é que caracterizam o desenvolvimento da ciência como uma atividade social, considerando tal desenvolvimento gradativo e que cada indivíduo, a partir do que já está consolidado, ao construir algo novo ou ao refletir sobre aquilo que já está edificado, coopera para o desenvolvimento da ciência.

Macias-Chapula (1998, p. 136) menciona que “[...] na verdade, a ciência necessita ser considerada como um amplo sistema social, no qual uma de suas funções é disseminar conhecimentos. Sua segunda função é assegurar a preservação de padrões, e a terceira é atribuir créditos e reconhecimento para aqueles cujos trabalhos têm contribuído para o desenvolvimento das idéias em diferentes campos."

A construção de novos conhecimentos e o desenvolvimento da ciência deve se dar a partir dos conhecimentos primeiros e da assimilação das informações que referenciam tais conhecimentos, sendo esses devidamente creditados a seus autores por meio da citação, que é o modo mais comum de atribuir crédito e reconhecimento.

Nesse contexto, a Ciência da Informação, cujo objeto de estudo é a informação, reflete sobre a transferência desses conhecimentos por meio do desenvolvimento de processos e técnicas de construção, comunicação e uso da informação com o objetivo de buscar assegurar a apreensão de sentido ou estado de consciência em seu significado. 


\section{A CIÊNCIA DA INFORMAÇÃO E SUA CONTRIBUIÇÃO PARA A CIÊNCIA}

O aumento da capacidade de multiplicação e armazenamento de informação explica boa parte da explosão da informação - ou, mais exatamente, explosão da quantidade de informação - que apresenta um crescimento do tipo exponencial (LE COADIC, 1996). O desenvolvimento e a convergência da eletrônica, da informática e das telecomunicações comunicação de informação à distância - após os meados do século XX, além de reforçarem essa tendência de crescimento, afetaram consideravelmente a Ciência da Informação, gerando importante mutação epistemológica na área: a ênfase nos estudos tradicionais com foco no acesso ao documento evolui e volta-se, particularmente, para estudos de sistemas de recuperação de informação, informação essa entendida como conjunto significante, instrumento de apreensão de sentido ou de estados aos seus significados.

A mutação epistemológica do domínio da Ciência da Informação tem como implicações outras prioridades sobre os seus objetos de ensino e pesquisa, constituídos, na atualidade, primordialmente, dos seguintes assuntos: informação assistida por computador, lingüística/produção de sistemas documentários, análises bibliométricas, infométricas e cientométricas, monitoramento, ciências cognitivas, teorias do conhecimento, processos heurísticos, redes neuronais, desenvolvimento de softwares, sistemas especialistas, hipermídia, modelagem de utilizadores de informação, economia da informação, propriedade intelectual, produtos e bens intangíveis.

A convergência de tais objetos de estudo reuniu, pela sua natureza e de forma simultânea, tanto as condições que favoreceram o fenômeno da explosão da informação, quanto também aquele da implosão do tempo, resultando no aparecimento de elevados fluxos de informação, ou seja, circulação de consideráveis quantidades de informação por unidade de tempo (LE COADIC, 1996). Os computadores atingem altas velocidades de processamento de dados. Os sistemas de telecomunicações chegam às mais distantes regiões do mundo em poucos segundos. Os sistemas eletrônicos encurtam o tempo necessário para coleta, tratamento e utilização da informação na tomada de decisão. 
A mudança no suporte da mensagem do significado transmitido a um ser consciente, na sua dimensão espacial temporal, propicia elevar o status da Ciência da Informação para o nível das ciências pós-modernas, da não linearidade, da interdisciplinaridade, ao mundo do complexo, que não aceita reduções, simplificações, mas, ao contrário, aproximações sucessivas de conhecimentos. Reunidas tais condições, na visão de Wersig (1993, p. 4) "[...] os atores (indivíduos, grupos, organizações ou culturas) precisam de ajuda [...] e o principal objetivo da Ciência da Informação é ajudar as pessoas (ou mais além: atores) que estão confusas pela situação do uso do conhecimento." Por meio do seu objeto de estudo, a informação, a Ciência da Informação busca harmonizar o homem com o seu destino.

Wersig (1993, p. 4) ainda ressalta:

[...] através dos séculos o papel do conhecimento para indivíduos, organizações e culturas mudou em muitos modos, e essas mudanças tornaram-se evidentes a partir do início do século XX, mais especificamente nos anos 60, quando se tornaram parte de um amplo movimento chamado de pós-moderno. Surge, então, a Ciência da Informação pós-moderna que é marcada por algumas mudanças na relação do utilizador com o conhecimento.

O autor afirma que há quatro fatores que apresentam relevância para essa questão:

\section{Despersonalização do conhecimento: tecnologia da comunicação}

Antes da invenção das tecnologias de impressão, o conhecimento era individual e sua transmissão era realizada por meio da oralidade. Mesmo com o advento das técnicas da escrita, quando o conhecimento podia ser registrado e armazenado, a disseminação ainda era condicionada pela capacidade de leitura e o conhecimento ainda era transferido oralmente. Gutenberg possibilitou, por meio da instalação das tecnologias da impressa, que mais pessoas registrassem seus conhecimentos individuais e os apresentassem a outras pessoas. Dessa forma, podemos dizer que a transmissão do conhecimento era personalizada, ou seja, havia uma relação direta entre o emissor e o destinatário da mensagem (receptor).

$\mathrm{Na}$ história das ciências, essa personalização do conhecimento tem o mais importante papel durante os primeiros séculos; como exemplo podemos citar as academias como lugares onde o conhecimento científico era discutido e apresentado. Esse estado de acesso ao conhecimento começou a sofrer alterações na segunda metade do século XIX, quando os processos de impressão tornaram-se processos de massa. 
A partir de então, o conhecimento passa a ser transmitido independentemente do emissor devido à introdução de processos de transmissão não oral, como, por exemplo, a tipografia e o papel industrializado. Ocorre, então, a despersonalização do conhecimento, ou seja, ocorre um distanciamento entre o emissor e o receptor da mensagem (do conhecimento).

Tal fenômeno se intensifica com a chegada das novas tecnologias de comunicação que são ainda mais despersonalizadas: bancos de dados on-line, cd-rom, correio eletrônico, discos ópticos, sistemas multimídias etc. $\mathrm{O}$ crescimento vertiginoso da capacidade de armazenamento de dados em meios legíveis por computador, meios magnéticos e, mais recentemente, meios óticos, não foi ainda suficiente para tornar viável o armazenamento generalizado em computador dos conhecimentos gerados pela atividade científica.

Em face da impossibilidade para se colocar disponível em sistemas em linha, ou seja, sistemas que permitam um certo grau de interação, de conversação em tempo real entre o corpo de conhecimento, representado pela literatura técnico-científica - fruto mais óbvio e mais facilmente sujeito à mensuração da atividade científica - e os pesquisadores, é mandatário que o conhecimento registrado na literatura sofra um processo de tradução, de representação, transformando-se em metaconhecimento.

Do ponto de vista operacional, essa tradução é realizada por intermédio de esquemas simbólicos que descrevem tanto a forma física, quanto o conteúdo informacional das obras que estão sendo registradas. O que vai ser armazenado nas grandes bases de dados é uma metáfora da informação original, é o conhecimento virtual, que só existe em função do seu referente, da sua vinculação remota com algum conhecimento real.

A criação dessas representações, que requer a conjunção de técnicas e processos comunicacionais complexos, é factível via linguagens documentárias, que são linguagens artificiais geralmente derivadas da linguagem natural.

Tais linguagens são chamadas artificiais porque não resultam de processo evolutivo e necessitam de regras explícitas para seu uso. Normalmente as linguagens documentárias estabelecem uma relação unívoca entre o termo e o conceito, isto é, entre o significante e o significado. Cada termo corresponde a um conceito do sistema de conceitos da área específica. A construção de tais linguagens constitui um processo científico complexo e longo.

\section{$>$ Credibilidade do conhecimento: tecnologia da observação}


A despersonalização do conhecimento faz com que ocorra também a necessidade de validar os conhecimentos. Durante um longo período, os métodos de observação e as tecnologias eram absolutamente simples e quem procurava provar alguma coisa podia fazer isso numa escala de esforço relativamente pequena. Mas, a partir do início do século XX, as técnicas de captação do conhecimento (tecnologias, metodologias de pesquisas, teorias) tornaram-se mais e mais sofisticadas, conduzindo, em várias áreas da ciência, a uma situação em que o conhecimento produzido dificilmente podia ser entendido ou provado.

Um dos fatores mais importantes para a aquisição do conhecimento é a pessoa de quem o conhecimento se origina. Se cada vez mais o conhecimento se torna despersonalizado, e por outro lado, cada vez mais o conhecimento tem de ser crível, as pessoas são colocadas numa situação na qual têm que decidir em o que aceitar como conhecimento ou em qual conhecimento acreditar.

Em face da necessidade de decidir sobre o que aceitar ou em que acreditar como conhecimento, o problema que se coloca não é o acesso à informação. É o de se colocar em correspondência uma representação de necessidade de um pesquisador, de uma comunidade científica com uma representação do conteúdo dos documentos, por meio de uma função de comparação que avalia a pertinência e a relevância dos documentos de forma que as informações recuperadas representem o estado da arte do conhecimento científico em determinado campo do conhecimento.

Para tanto, são necessárias - além das ações de construção de bancos de dados, de sistemas de codificação, de indexação de arquivos e linguagens de acesso - aptidões para: selecionar, avaliar, formalizar e validar a informação; estabelecer regras e práticas comuns; estabelecer referências; implantar ferramentas que democratizem a informação; assegurar-se que as referências estão sendo compartilhadas por quem de direito; criar ferramentas de orientação, de relacionamentos entre os diferentes documentos; definir regras de circulação e de prioridades de acesso à informação.

Trata-se, assim, de um processo de explicitação de métodos, de formas operacionais e de comportamento. Para tanto, a presença de profissionais de informação deve ser solicitada para desempenhar um papel muito mais importante enquanto produtores de conhecimento, cabendo formular estratégia de ação como agentes sociais, privilegiando, nas suas formações, competências sobre o domínio e a rentabilização de fluxos de informação. 
Para assegurar estratégias de busca de informações relevantes para um propósito, destaca-se a necessidade de uma seleção sistemática e otimizada das informações obtidas. Processo aparentemente simples, o discernimento na recuperação sistemática de informações úteis e críticas 1 é, no mundo globalizado, o fator determinante para a produção do conhecimento científico e da força econômica dos países.

A operação para buscar informações úteis e críticas exige procedimentos cada vez mais otimizados por meio de desenvolvimentos de processos, metodologias e ferramentas, aliados ao conhecimento das fontes adequadas ao propósito da busca.

\section{Fragmentação do conhecimento: tecnologia de apresentação}

O conhecimento tem-se tornado cada dia mais fragmentado. Uma das razões é o imenso volume de conhecimento que torna impossível para qualquer pessoa acumular todos os conhecimentos disponíveis. Uma segunda razão é o que Weber, (1968) chamou de “autonomização das áreas de ação", significando que cada vez mais os diferentes campos de ação desenvolvem padrões diferentes para si, tornando-se autônomos uns em relação aos outros. A terceira razão é a passagem do que Parsons, (1969) chamou de "[...] sistemas finais, como ideologias ou religiões, conduzindo à situação do pluralismo de pensamentos e visões de mundo."

A fragmentação do conhecimento - fenômeno que eleva o nível de complexidade dos processos de gestão e apropriação da informação - requer formas sofisticadas de identificação, acesso e recuperação da informação, destacando-se, entre essas, o estudo das estruturas de informação em rede, compartilhando conhecimento de diferentes áreas. Ela é também responsável pela diversificação das tecnologias de apresentação do conhecimento. A palavra escrita e impressa agora coexiste com uma grande variedade de tecnologias não-conectadas e conectadas (editoração eletrônica, gráficos computadorizados, animação computadorizada, bancos de dados) e também com um sistema cada vez mais diversificado de organizações e mídias de apresentação do conhecimento.

\footnotetext{
${ }^{1}$ Informações úteis e críticas: informações cuja não aquisição e não mobilização do conhecimento, no tempo requerido, podem comprometer, de forma irremediável, os objetivos maiores da empresa.
} 
Assim, para não perder o essencial da informação e para assegurar a cobertura mais completa possível do assunto analisado, a partir de uma massa considerável de dados e/ou de informação, a questão que se impõe é a de encontrar técnicas que permitam extrair sentido nessa massa de informação, sem, no entanto, ter que ler documento por documento, o que tornaria inviável o processo (SANTOS, 2002).

É, precisamente, papel dos softwares infométricos auxiliar os profissionais de informação no processo de recuperação e de agregação de valor às informações recuperadas. Essas ferramentas facilitam a abordagem global de uma massa de informação, respondendo a quatro tipos de necessidades, conforme o Quadro 1:

\begin{tabular}{|c|c|c|c|}
\hline \multicolumn{4}{|c|}{ Quadro 1: Necessidades de informações $x$ tratamentos requeridos } \\
\hline Necessidades & Tratamentos & Resultados & Softwares \\
\hline \multicolumn{4}{|c|}{ Análise de "Corpus Estruturado" } \\
\hline $\begin{array}{l}\text { Exploração } \\
\text { Posicionamento }\end{array}$ & $\begin{array}{l}\text { Contagens simples sobre } \\
\text { um campo }\end{array}$ & \begin{tabular}{|ll}
$\square$ & Autores mais importantes \\
$\square$ & Empresas mais importantes \\
$\square$ & Publicações mais citadas \\
$\square$ & Temas mais importantes
\end{tabular} & \begin{tabular}{|l}
. DATAVIEW + \\
(Excel, Statistic...) \\
. TETRALOGIE \\
. DATALIST \\
. TECHNOLOGY \\
WATCH \\
. TOA (Technology \\
Opportunities \\
Analysis) \\
\end{tabular} \\
\hline Estruturação & $\begin{array}{l}\text { Cotejamentos, } \\
\text { comparações entre dois } \\
\text { campos ou do campo } \\
\text { com ele mesmo. }\end{array}$ & $\begin{array}{|ll|}\square & \text { Redes de autores (equipe) } \\
\square & \text { Redes de temas } \\
\square & \text { Disposições de autores e temas } \\
\square & \text { Equipes posicionadas por temas } \\
\text { chaves }\end{array}$ & \\
\hline $\begin{array}{l}\text { Estruturação } \\
\text { Prospecção }\end{array}$ & $\begin{array}{l}\text { Cotejamentos, } \\
\text { comparações de dois } \\
\text { campos com um terceiro. } \\
\text { Ex. a data, para } \\
\text { visualizar a evolução no } \\
\text { tempo }\end{array}$ & \begin{tabular}{|ll}
$\square$ & Estabilidade das equipes \\
$\square$ & Emergência de novos temas \\
$\square$ & Mobilidade dos autores nos \\
& temas \\
$\square$ & Mobilidade dos pesquisadores \\
& entre os laboratórios \\
$\square$ & Etc. \\
\end{tabular} & \\
\hline \multicolumn{4}{|c|}{ Análise de Textos Livres } \\
\hline Exploração & Contagens simples & $\begin{array}{l}\text { Palavras ou expressões mais } \\
\text { importantes }\end{array}$ & $\begin{array}{l}\text { Vários extratores } \\
\text { terminológicos: } \\
\text {. SEMIOMAP } \\
\text {. SAMPLER } \\
\text {. TEXT } \\
\text { NAVIGATOR } \\
\text {. EVALOG } \\
\text {. LEXIMAPPE } \\
\text {. SDOC } \\
\text {. NEURODOC } \\
\text {. GINGOi }\end{array}$ \\
\hline
\end{tabular}




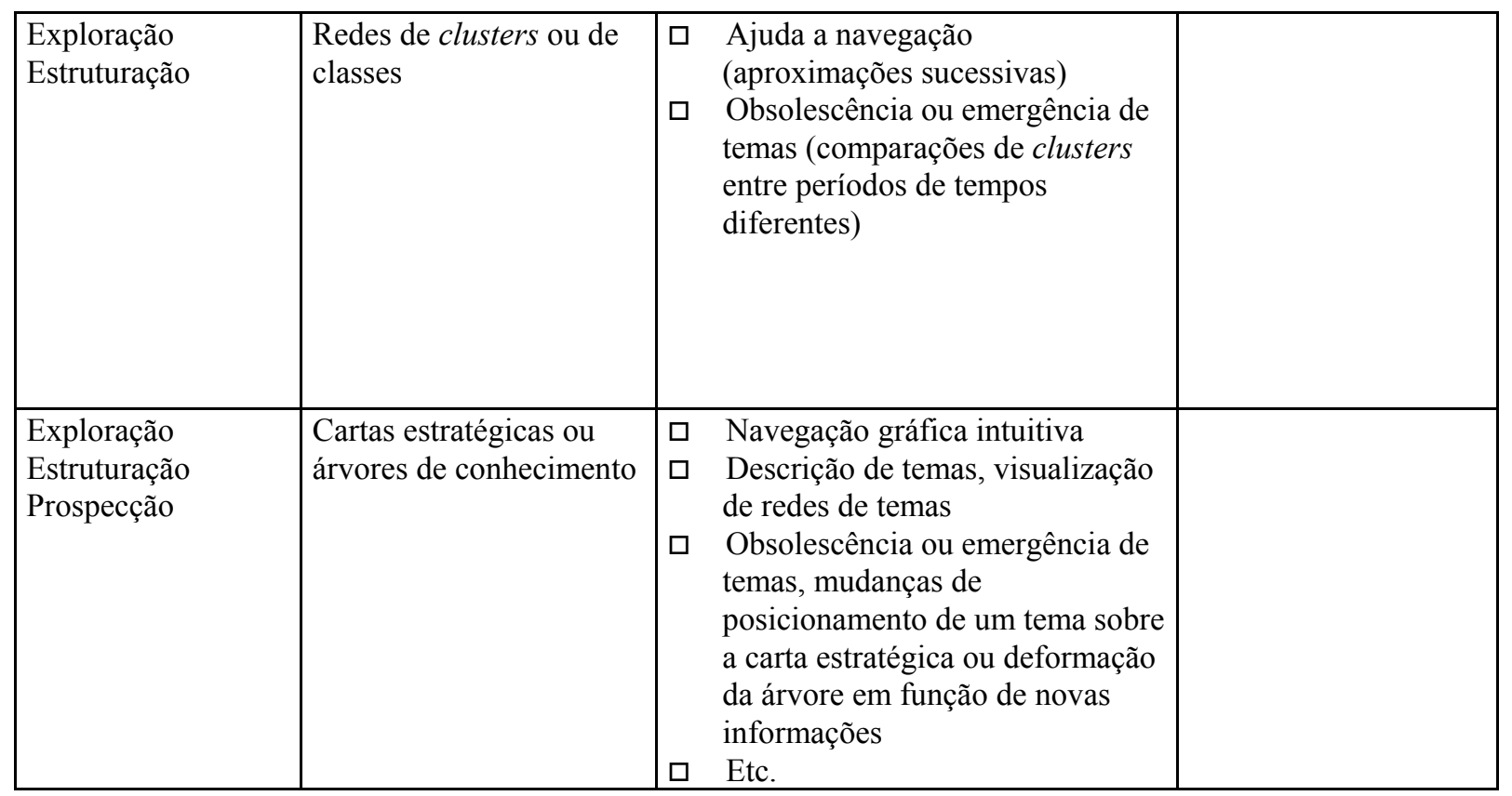

Fonte: (ROUSEAU-HANS \& THIL, 1997)

O Quadro 1, que sintetiza as necessidades acima, apresenta os resultados que podem ser obtidos em função do tipo de tratamento realizado. Duas situações foram consideradas: uma para informações em formato bibliográfico "corpus estruturado"; e outra para análise realizada a partir de textos livres. Para um caso ou outro, os softwares mais conhecidos para essas análises estão listados na última coluna à direita.

\section{Racionalização do conhecimento: tecnologia da informação}

$\mathrm{Na}$ atualidade, para se apropriar de uma cultura informacional, racionalizar o conhecimento, isto é, organizá-lo de forma a atender as demandas existentes, faz-se necessário dotar-se também de uma cultura tecnológica. E, mais ainda, para que se possa postular, sem o risco de ser estigmatizado de cientificismo, faz-se necessário assumir que não existe ciência sem tecnologia e nem tecnologia sem ciência.

Uma avalanche de informações eletrônicas na rede Internet e as aplicações eletrônicas a ela relacionadas (jornais, livros, revistas, fóruns, conferências, sites, bibliotecas, museus etc) como também a progressiva automatização dos métodos de trabalho ilustram o fenômeno, o que torna desnecessário justificar exaustivamente o fato. Dos dispositivos de entrada e saída de dados - equipamentos terminais - aos dispositivos de transmissão - as linhas físicas ou ondas hertzianas -, passando pelos dispositivos de estocagem e de tratamentos - computadores -, todas as novidades técnicas da informação têm em comum: emitir, receber, veicular e memorizar, tratar sinais eletrônicos, ou seja, ondas de elétrons (ou de sinais ópticos - vagas de fótons). Daí o nome genérico de técnicas eletrônicas (e fotônicas) utilizado em substituição aos objetos materiais - átomos - e ao nome de técnicas de numerização (bits).

Esses novos referenciais evidenciam a relevância de uma ciência que auxilie os pesquisadores, as comunidades científicas, a ciência e a sociedade como um todo a selecionar, organizar, controlar, transferir e utilizar informações que possam produzir novos conhecimentos e serem úteis para o desenvolvimento da ciência, otimizando a disseminação e $o$ acesso às informações existentes. 
Para tanto, a Ciência da Informação, frente a uma ciência e a uma tecnologia movimentadas e turbulentas, realiza processos de estruturação e representação de informações, sendo esse trabalho materializado pelas bases de dados, bibliotecas digitais, catálogos bibliográficos e demais sistemas de recuperação de informação que são colocados à disposição do público. Desse fato, faz-se necessário o domínio sobre um conjunto explosivo quanto ao número e à variedade de conhecimentos científicos e técnicos que se destacam por:

uma ininterrupta aparição de conceitos, métodos, modelos, de leis, etc.

um crescimento exponencial de emissão de sinais elétricos produzidos, de capacidade de digitalização, dos fluxos de tratamentos de dados informatizados, etc.

Tal fato requer uma atenção crítica e um trabalho de conceitualização refinado. Para que isso seja feito, somente um caminho pode permitir a empreitada: o processo epistemológico (a filosofia das ciências e das técnicas), acompanhado por um processo histórico (a história das ciências e das técnicas) e suportado por ele.

\section{CONCLUSÃO}

Conforme o que aqui se apresenta, o armazenamento, a conservação e o acesso à informação são resultado de uma evolução que vem desde o advento da imprensa, e são objetos de longos estudos e de interesses social e econômico fundamentais para a sociedade denotada na atualidade de sociedade da informação.

Cultura tecida no âmago da Ciência da Informação, sua preocupação central tem como foco evidenciar uma dimensão social concreta, aquela de uma informação: um significado transmitido a um ser consciente - um ser social em busca do conhecimento. Essa Ciência se situa no contexto das ciências pós-modernas, interdisciplinares, que se constituem o principal meio de acesso a uma compreensão do social e do cultural.

Com efeito, esses recursos de acesso não produzem somente informação, eles são também portadores de mutação epistemológica - passagem do estudo do documento por aquele da informação -, e, do ponto de vista do objetivo da Ciência da Informação, se materializam por meio dos sistemas de recuperação de informação que consistem em colocar em correspondência uma representação de necessidade de um pesquisador, de uma comunidade científica com uma representação do conteúdo dos documentos, por meio de uma função de comparação que avalia a pertinência e relevância dos documentos. 
Dessa forma, para que as informações recuperadas representem o estado da arte do conhecimento científico em determinado domínio, produzindo um novo estado do conhecimento, é necessária uma visão mais aprofundada das necessidades informacionais, que rompa com a superficialidade e a forma simplista com que muitas vezes tais questões são tratadas.

Reforçam-se, assim, a relevância e a importância de uma ciência que reflita sobre recursos e dispositivos propulsores de fluxos informacionais para geração de novos conhecimentos por meio de uma abordagem interdisciplinar, uma vez que a essência da ciência é a própria informação.

\section{REFERÊNCIAS}

ALVES, A. D. A “revisão da bibliografia” em teses e dissertações: meus tipos inesquecíveis. Cad. Pesq. São Paulo, n. 81, p. 53-60, maio. 1992.

BARreto, A. de A. A questão da informação. São Paulo em Perspectiva, São Paulo, v. 8, n. 4, p. 3-8, 1994.

BROOKES, B. C. The foundations of information science. Journal of Information Science, n. 2, 1990.

MACIAS-CHAPULA, C. A. O papel da informetria e da cienciometria e sua perspectiva nacional e internacional. Ciência da Informação, Brasília, v. 27, n. 2, p. 134-140, maio/ ago. 1998.

LE COADIC, Y.-F. A Ciência da Informação. Tradução de Maria Yeda F. S. de Figueiredo Gomes. Brasília, DF: Briquet de Lemos, 1996.

LE COADIC, Y.-F. Princípios científicos que direcionam a ciência e a tecnologia da informação digital. Transinformação, Campinas, v. 16, n. 3, p. 205-213, set./ dez. 2004.

PARSONS, Talcott. Sociedades: perspectivas evolutivas e comparativas. São Paulo : Pioneira, 1969.

ROBREDO, J. Da Ciência da Informação revisitada aos sistemas humanos de informação. Brasília: SSRR Informações; Thesaurus, 2003.

ROUSEAU-HANS, F.; THIL, J. Veille et informatique: des besoins aux solutions. Strasbourg. Technologies Internationales, n. 39, p. 33-36, nov. 1997.

SANTOS, R. N. M. dos. Métodos e Ferramentas para Gestão de Inteligência e do Conhecimento. Perspectivas em Ciência da Informação, Belo Horizonte, v. 5, n. 2, p. 205215,2000 . 
SAYÃO, L. F. Bases de dados: a metáfora da memória científica. Ciência da Informação, Brasília, v. 25, n. 3, p. 1-6, set./dez. 1996.

SILVA, A. M. da. Conhecimento/informação: sinonímia e/ou diferenciação?. In: RODRIGUES, G. M.; LOPES, I. L. (orgs.). Organização e representação do conhecimento na perspectiva da Ciência da Informação. Brasília: CID; UNB, 2003. (Estudos Avançados em Ciência da Informação, v. 2).

WEBER, Max. História geral da economia. São Paulo, Mestre Jou. 1968.

WERSIG, G. Information Science: the study of postmodern Knowledge usage. Information Processing \& Management, v. 29, n. 2, p. 229-239, 1993.

\begin{abstract}
Face to the new knowledge status, basically consisting of dispersonalization, credibility and fragmentation, decurring from the immense increase of information and knowlege currently existing, Information Science, having information as study object, contributes to scientific knowledge production. It aims at researching and developing processes, techniques, taking over information technologies and cognition and knowledge techniques for information to produce its effects: seeking for granting aprehension of sense or change in conscience status in meaning, i.e., the knowledge. Thus, science social character turns out concrete. By reflecting about Information Science fundaments, we intend to show that construction, communication and use operations which take place over its object of study materialize in information retrieval systems. In practice, such systems consist of corresponding a representation of the researcher's necessity, or of a scientific community, with a document content representation, by means of a comparison function which assesses document pertinence and relevance, so that the information recovered may represent scientific state-ofthe-art on a determined knowledge field.
\end{abstract}

KEY-WORDS: Information Science. Knowledge Production. Information Retrieval Systems.

Originais recebidos em 29/05/2006 